\title{
Knowlegde and willingness to donate eye among medical doctors in delta state
}

\author{
${ }^{1}$ Abadom E.G, ${ }^{1}$ Otene C.I, ${ }^{2}$ Enivwenae A.O. \\ ${ }^{I}$ Department of Surgery, Faculty of Clinical Medicine, College of Health Sciences, Delta State University, \\ Abraka. \\ ${ }^{2}$ Department of Surgery, Federal Medical Centre, Asaba.
}

\begin{abstract}
BACKGROUND: Corneal blindness accounts for about 6-8 millions of blind persons in the world with 90\% of these persons living in developing countries. Corneal transplantation therefore offers the potential for sight restoration. However, it is hugely dependent on voluntary eye donation and attitude of medical professionals to eye donation is quite important because they are in close contact with the prospective donor and their relatives. They can therefore increase eye donation rates.
\end{abstract}

AIM: This study was done to determine the knowledge and willingness to donate eyes in doctors in Delta State and factors influencing the willingness to donate.

METHODS: This was a cross sectional study carried out among doctors in Delta State. Structured questionnaire was administered.

RESULTS: Eighty two (75.9\%) medical doctors were aware of eye donation after death. The mass media was the largest source of first information (51.7\%). Sixty -two (57.4\%) medical doctors correctly indicated that cornea is the part of the eye donated and fifty-seven (52.7\%) knew that the donated eye is used for cornea transplant. Forty three (39.8\%) correctly answered that the ideal time to collect the donated eye is within 6 hours. Only 36 respondents (33.3\%) were willing to donate their eyes for transplant. The main reasons for unwillingness were poor knowledge of donation process to take a decision and family objection.

CONCLUSION: Our study showed relatively low level of knowledge and willingness to donate eyes for corneal transplant.

Keywords: awareness, knowledge, eye donation, willingness, corneal transplant, Delta State.

\section{Introduction}

Corneal blindness accounts for about 6-8 millions of blind persons in the world with $90 \%$ of these persons living in developing countries. ${ }^{1}$ While $82 \%$ of overall blindness worldwide is found in those aged 50 years or older, corneal blindness in developing countries affects a significantly younger population than other forms of blindness. ${ }^{2}$ Corneal blindness impacts many in their most productive years and indicates that the corneal blindness population could have a greater total (Disability Adjusted Life Years) DALYs than the cataract blindness population ${ }^{3}$.

The major causes of corneal blindness in developing countries include trachoma, corneal ulceration following infections, ocular trauma, use of harmful traditional eye medications, onchocerciasis, xerophthalmia due to vitamin A deficiency, ophthalmia neonatorum ${ }^{1}$. In Nigeria, corneal blindness ranked forth as a cause of blindness when trachoma and onchocerciasis were excluded ${ }^{4}$.Though in all cases of corneal blindness, prevention is more cost effective in decreasing the prevalence of blindness there is a tendency that those who are already blind from corneal diseases tend to remain blind throughout life ${ }^{1}$.

Corneal transplant is a sight saving procedure and is the most common type of human transplant surgery ${ }^{5}$. Corneal transplantation therefore offers the potential for sight restoration for those who meet the criteria. However, it is hugely dependent on voluntary eye donation by suitable donors and amongst other requirements is a well-established eye bank ${ }^{6}$.

To effectively meet the demands of corneal transplantation in Nigeria, a corneal bank must be established in the country and eligible citizens should voluntarily register to donate their eyes upon death. A study done amongst medical students in South Eastern Nigeria, showed that though a high proportion were aware of eye donation, they lacked adequate knowledge in some aspects of eye donation and about $66.4 \%$ were unwilling to pledge their eyes for donation. ${ }^{7}$ In another study done by Waziri-Erameh et al amongst Ophthalmologist, only $21 \%$ agreed to donate their eyes at death ${ }^{.8}$

The attitude of medical professionals to organ donation is quite important because they are usually the first point of contact with the prospective donors and their relatives. They will probably be able to initiate the process of obtaining consent from relatives to donate organs and may be directly involved in the postmortem process of harvesting the tissues for 
transplantation. The awareness, knowledge and willingness of doctors to donate their eyes will likely influence their role in organ/tissue donation process.

This study was done to determine the knowledge and willingness to donate eyes in doctors in Delta State and factors influencing the willingness to donate. This will form a basis to educate this group of people who play an important role in organ and tissue donation process.

\section{Method}

This was a cross sectional study carried out among doctors in Delta State while they attended an important annual general meeting. Considering that it was an elective year, there was good representation from all zones of the state. Structured questionnaire was administered after a written consent form was given to each participant and participation was voluntary. Questionnaire included demographics, awareness, knowledge, cultural /spiritual beliefs on donation of eyes. "Awareness" was considered as having a realization about the fact that a dead individual's eyes can be utilized to give vision to those blind from corneal disease. "Knowledge" was considered as having understanding regarding the details of different aspects of eye donation like pledging of eyes, when can eyes be donated, and importance of one's relative in making a decision and getting approval to collect donated eyes.

Statistical analyses were performed by using the Statistical Package for the Social Sciences software, SPSS version16. The population was assessed with descriptive studies. Univariate and multivariate logistic regression analysis models assessed the relationships between gender, age, religion, ethnic group, and willingness to donate. A two-tailed $P$ value of less than 0.05 was considered statistically significant.

\section{DEMOGRAPHICS}

\section{Result}

A total of 150 doctors were administered questionnaires but 108 could be retrieved representing a response rate of $72 \%$. The doctors that participated in this survey cut across almost all ages ranging from about 25 to 59 years, most of them were in the age range of 30-39years (46.3\%). Table 1 is a summary of the age distribution of the medical doctors. There was a male preponderance $78.6 \%$.

$70(64.8 \%)$ were married, 32(29.6\%) were single, 3(2.7\%) were divorced while 3(2.7\%) were widowed. Most of them, $97(95.1 \%)$ were Christians, $8(7.4 \%)$ were Muslims and others, 3(2.7\%) did not indicate their religion. $68.5 \%$ have only MBBS while $25(23.1 \%)$ are specialists with various Fellowships and another $9(8.3 \%)$ have various masters degrees in addition to their MBBS.

Over $85 \%$ of the respondents have spent at least 5 years in practice as medical doctors. Most of them have practiced between 5 and 9 years. Table 2 is a summary of the distribution of years of qualification.

Table 1: Age distribution of medical doctors

\begin{tabular}{ll}
\hline \hline AGE (yrs) & FREQUENCY (\%) \\
\hline $20-29$ & $7(6.5)$ \\
$30-39$ & $50(46.3)$ \\
$40-49$ & $32(29.6)$ \\
$50-59$ & $19(17.6)$ \\
\hline TOTAL & $108(100.0)$ \\
\hline \hline
\end{tabular}

The predominant tribes were Ibo (32.4\%), Urhobo (23.1\%), Isoko (11.1\%) and Itsekiri (8.3\%).

Table 2: Years of qualification of medical doctors

\begin{tabular}{lll}
\hline Years of Qualification & Frequency & Percent $(\%)$ \\
\hline Less than 5 years & 20 & 18.9 \\
5 to 9 years & 33 & 30.6 \\
10 to 14 years & 21 & 19.8 \\
15 to 19 years & 6 & 5.6 \\
$\geq 20$ years & 12 & 11.3 \\
Not indicated & 15 & 13.8 \\
\hline Total & 108 & 100.0 \\
\hline
\end{tabular}




\section{Awareness And Knowledge}

Eighty two (75.9\%) medical doctors were aware of eye donation after death. Majority of the doctors first heard of eye donation through the print media (30.5\%). Table 3 shows the first source of information on eye donation. The mass media was the largest source of first information $(51.7 \%)$.

Sixty -two (57.4\%) medical doctors correctly indicated that cornea is the part of the eye donated and fifty-seven $(52.7 \%)$ knew that the donated eye is used for cornea transplant. Forty three (39.8\%) correctly answered that the ideal time to collect the donated eye is within 6 hours. Table 4 shows the responses to some of the questions on knowledge of eye donation.

Knowledge of cornea for donation was not related to sex $(\mathrm{p}=0.87)$, age $(\mathrm{p}=0.09)$ or tribe of the doctor $(\mathrm{p}=1.25)$. Years of qualification and presence of additional qualification was also not significantly associated with knowledge on corneal transplantation.

Table 3: First information on eye donation

\begin{tabular}{lll}
\hline First source of information & Frequency & $(\%)$ \\
\hline Have not heard of eye/corneal donation & 26 & 24.0 \\
Print media & 33 & 30.5 \\
Electronic media & 23 & 21.2 \\
Lecture & 18 & 16.7 \\
Seminar & 3 & 2.8 \\
Conference & 1 & 0.9 \\
Did not indicate & 4 & 3.7 \\
\hline Total & 108 & 100.0 \\
\hline
\end{tabular}

Table 4: Response to questions on knowledge of cornea donation

\begin{tabular}{lc}
\hline $\begin{array}{l}\text { What part of the eye is donated } \\
\text { (Correct answer in bracket) }\end{array}$ & Frequency (\%) \\
\hline & $62(57.4)$ \\
Cornea(T) & $11(10.2)$ \\
Lens (F) & $19(17.6)$ \\
Retina (F) & $5(4.6)$ \\
Optic nerve (F) & $11(10.2)$ \\
Cornea and any of the parts the eye & \\
above(F) & \\
\hline What is the donated eye used for? & $57(52.7)$ \\
\hline & $18(16.7)$ \\
Corneal transplant (T) & $4(3.7)$ \\
Replace the whole eye (F) & $23(21.3)$ \\
Lens transplant (F) & $6(5.6)$ \\
I do not know & \\
No response & \\
\hline When is the ideal time to collect the & \\
donated part? & $43(39.8)$ \\
\hline & $41(37.9)$ \\
First 6 hours (T) & $5(4.6)$ \\
First 24 hours (T) & $19(17.6)$ \\
First 48 hours (F) &
\end{tabular}

Sixty- five $(60 \%)$ medical doctors indicated that the ophthalmologist/plastic surgeons and all doctors can be trained to collect the donated eye.

\section{WILLINGNESS TO DONATE}

Interestingly, despite being doctors, majority, 63(58.3\%) of the respondents were not willing to donate or pledge their eyes for donation. Only 36 respondents $(33.3 \%)$ were willing to donate their eyes for transplant to a recipient in need. Nine medical doctors $(8.3 \%)$ were undecided. Willingness to donate was significantly associated with decreasing age $(\mathrm{p}=0.004)$, the male sex $(\mathrm{p}<0.000)$. Religion, ethnic group or number of years post qualification was not significantly associated with willingness to donate. 


\section{REASONS FOR WILLINGNESS TO DONATE}

Among the 36(33.3\%) doctors who were willing to pledge or donate their eyes or part of it,19(53.0\%) felt that it will help restore sight to blind followed by being a noble act,5(13.9\%) and helping the blind and also being a noble act5(13.9\%) were the commonest reasons. Table 5 shows the reasons for the willingness to donate.

Table 5 shows the reasons for the willingness to donate.

\begin{tabular}{lll}
\hline Reason for willingness to donate & Frequency & Percent \\
\hline A noble act & 5 & 13.9 \\
Will help the blind & 19 & 53.0 \\
Example to others & 2 & 5.5 \\
Other reason(s) & 1 & 2.78 \\
Noble act \& will help the blind & 5 & 13.9 \\
Noble act, will help the blind \& & 2 & 5.5 \\
example to others & 1 & \\
No reasons given & 1 & 2.8 \\
All reasons given & 36 & 2.8 \\
\hline Total & 36.0 \\
\hline
\end{tabular}

\section{REASONS FOR UNWILLINGNESS TO DONATE}

The commonest reason for unwillingness to donate was a need for more information to make a decision $25(40.0 \%)$ followed by objection by family members 11(17.4\%). Table 6 shows the different reasons for unwillingness to donate.

Table 6: Reasons for unwillingness to donate

\begin{tabular}{lll}
\hline & Frequency & Percent \\
\hline Against Religion & 3 & 4.7 \\
Against cultural beliefs & 2 & 3.0 \\
Family members will object & 11 & 17.4 \\
May be used for illegal trade & 5 & 7.9 \\
Cultural beliefs \& Family members & 1 & 2.0 \\
will object & 5 & 7.9 \\
Family members will object \& & & \\
May be used for illegal trade & 4 & 6.0 \\
Against sacredness of the body & 25 & 40.0 \\
Require more info for decision & 2 & 3.0 \\
No particular reason & 2 & 3.0 \\
Part may be missing on reincarnation & 2 & 3.0 \\
Against religion \& sacredness of body & 1 & 2.0 \\
Will disfigure the face post-mortem & & \\
\hline Total & 63 & 100.0 \\
\hline
\end{tabular}

In response to a mandatory next of kin consent before eyes pledged or donated can be taken, only 41 respondents $(38.0 \%)$ believed next of kin consent should be mandatory, while more respondents, $60(55.6 \%)$ did not think it should be mandatory to have the consent of the next of kin and 7 (6.5\%) were undecided.

\section{Discussion}

This study was done amongst homogenous group of people with high level of education, socioeconomic status and practicing medical doctors. Most of the doctors were male, married, Christians with an age range 25 years to 59 years and $67 \%$ had more than 5 years post qualification experience. These are the group of people expected to have good knowledge of organ and tissue donation and transplant than the general 
public. They can be good motivators and spoke persons for donation because they are in close contact with potential donors and their relatives.

\section{Awareness And Knowledge}

The level of awareness of corneal donation was high but knowledge on basic information on corneal transplantation was surprisingly average. This is similar to the study done amongst medical students in South East Nigeria which showed inadequate knowledge in certain areas of eye/corneal transplantation ${ }^{7}$. It is probable that the level of knowledge in these doctors is a reflection of the inadequate knowledge as medical students. Medical students who are inadequately informed or uncomfortable with the idea of eye donation will obviously not be good spokespersons for eye donation, when they become doctors. ${ }^{7}$ In a similar study on medical students in Delhi, the level of awareness was $99.4 \%{ }^{9}$ while it was $79.6 \%$ in another study on medical students in India. ${ }^{10}$ In nursing students in Bangalore the level of awareness was $96.8 \%{ }^{11}$ while awareness of hospital staff on organ donation was $97 \% .^{12}$

In this study, only $57.4 \%$ of the medical doctors knew that the cornea is the part donated while $52.7 \%$ knew that the donated cornea is for corneal transplant and 39.8\% knew the ideal time to collect donated eyes. In the Delhi study, $86.1 \%$ knew the cornea is for cornea grafting though less than $50 \%$ knew the ideal time. ${ }^{9}$ In the study in India, $63.3 \%$ knew the ideal time to collect the eyes ${ }^{10}$. A study on attitude of health professionals towards cadaveric tissue donation revealed insufficient knowledge about cadaveric tissue donation and highlighted the importance of health professional education ${ }^{13}$.

Different factors could influence knowledge on eye donation in different parts of the world. In countries where there are established corneal transplant centres and eye banks, the knowledge on eye donation is expected to be high because efforts would have been made to increase the general public awareness and knowledge in other to improve potential donor pool.

In our study, knowledge was not associated with any demographic profile reflecting a general lack of in-depth knowledge. Increased knowledge can be achieved through mass media and incorporation of a module on organ/tissue donation in their training curriculum.

Most of the information on eye donation was through mass media and this shows that one of the important ways to increase the tissue supply for transplant is to increase public awareness through mass media. Enlightenment strategies which have been through the print, electronic media should be supplemented and misconceptions on eye donation eliminated.

Similar results were noted in other studies ${ }^{9-13}$.

\section{Willingness To Donate}

In this study, despite a high awareness, there was a low level of willingness to donate their eyes. Similar low levels of willingness were found amongst medical students in South East Nigeria $^{7}$ and Ophthalmologist ${ }^{8}$ in Nigeria. Several reasons could be responsible for this; it may be attributed to poor knowledge on eye donation and a need to address misconceptions on corneal donation ${ }^{7}$. Surprisingly in the study by Erameh-Waziri et al on willingness of ophthalmologist in Nigeria to donate their eyes only $21 \%$ of ophthalmologists were willing to donate their eyes ${ }^{8}$. Being the group of health professional who specialize in the treatment of eyes and performing eye surgeries, it may seem that knowledge alone may not be the only barrier to eye donation amongst the medical doctors but cultural and religious beliefs.

Other region-specific factors may influence the willingness to donate in different parts of the world because the willingness to donate was high in medical students in India ${ }^{9,10}$, nursing students in Bangalore ${ }^{11}$, health professionals in India ${ }^{14}$, adults in Singapore ${ }^{5}$, University students and the general population in Malaysia ${ }^{15,16}$. In United Kingdom only 10\% of people on the national Organ Donor Register are unwilling to donate their cornea. $^{18}$

Willingness to donate was significantly associated with decreasing age and male. The sample size of females in this study was small to determine this association. The younger population should be the core target of enlightenment campaigns. In United Kingdom the median age of eye only donors was 70-80 years while in United States it is $40-50$ years. ${ }^{18}$ The age of the donor contributes to the quality and usability of the cornea ${ }^{18}$

\section{Unwillingness To Donate}

Results in this study shows that the main reasons stated for unwillingness to donate was inadequate information on the eye donation to take a decision and family members' objection. This is similar to the study among medical students in Delhi. ${ }^{9}$ In other studies amongst UK nurses the main reason for refusal to donate specific tissues such as the eye, skin and bone with preference to other organs amongst UK nurses, Donation Coordinators and hospital health staff was the perceived impact on disfigurement postmortem which was not the same reason in this study. ${ }^{19-21}$ The unwillingness to donate eyes may also support the fact that awareness 
alone is not enough to influence or determine the willingness to donate eyes for corneal transplantation. It may be a reflection of the low knowledge on eye donation, the procurement process, cultural and religious beliefs. Thus it will be quite important that a more in-depth teaching on organ transplantation and the role of the doctor should be taught at first degree level in medical schools in Nigeria.

Another important reason could be the influence of the immediate extended family making key decisions in a family which has always been part of the culture. The study by Tandon et al showed that the prior knowledge of eye donation, literacy, and socioeconomic status had no influence on willingness for eye donation and major reasons for not donating eyes included refusal to discuss the issue and dissuasion by distant relatives, legal problems, and religious beliefs. ${ }^{22}$

Despite most of the doctors being Christians, this did not play a role in their decision to donate. Most of the religions worldwide favor organ transplantation, highlighting the important role of religious institutions in helping people to make the donation decision ${ }^{23-25}$. These religious heads can act as role models to the general public. Thus attention should also be focused on this category of people to properly educate them on their role in influencing the decisions of their congregation/ flock.

The study in Singapore ${ }^{5}$ showed that increased knowledge (awareness and specific knowledge), increased altruism (instrumental and terminal values), weaker spiritual beliefs and positive attitude towards corneal donation led to an increased willingness to donate. Weaker spiritual beliefs may not influence intention to donate in Nigerians who are generally religious but religious catalyst may. Gogate B et al ${ }^{23}$ stated that a catalyst can improve corneal harvesting rates and the identified catalysts such as certifying doctors and persons of faith (priests who perform the last rites) are the most obvious catalysts.

The main reason to donate was to help restore vision to the blind and the act of donating perceived as a noble act. Nobility in the act of eye donation was the main motivational force for eye donation according to $85.6 \%$ of nursing students ${ }^{11}$. This is similar to the study done in Singapore ${ }^{5}$ but different from studies done in Toronto $^{25}$ and India ${ }^{16}$. In Toronto, the main reason for donating was because of experiences with corneal donation and transplantation while in India, it was believed to be a way to live on after death. This shows the impact of culture/religion and interaction with donor recipients on willingness to donate.

More medical doctors felt there should be no mandatory next of kin consent before eyes pledged or donated can be taken. This is quite surprising because fewer proportions of doctors were willing to donate their eyes but it could reflect their aversion to family interference with decisions taken while alive. Individual opinion about organ donation is reported to be affected by age, religion, culture, and beliefs concerning death and mortality ${ }^{27-}$ 29.

A study by Eniola et al has also shown that guidance and counseling and legislation should be adopted to change peoples' negative attitude to eye donation and encourage voluntary donation ${ }^{30}$.

This could also contribute to enabling more doctors make decisions to become transplant surgeons and influence policies to establish transplant centres in Nigeria, if included.

\section{Conclusion}

Our study showed relatively low level of knowledge and willingness to donate eyes for corneal transplant. This is ominous because most people will seek their doctors' opinion before taking a major health decision. The main reasons for unwillingness were inadequate knowledge on eye donation in order to take a decision and objection by family members. This shows the importance of knowledge and socio-cultural belief.

Medical doctors have great potentials to motivate patients and families of ill patients which they constantly come in contact with if they know the benefits. Therefore, increased knowledge can be achieved through mass media and incorporation of a module on organ/tissue donation in their training curriculum.

This could also enable them make decision to become transplant surgeons and influence policies to establish transplant centres in Nigeria as well as educating prospective donors.

\section{References}

[1]. Whitcher JP, Srinivasan M, Upadhyay MP. Corneal blindness: a global perspective Bull. World Health Organization 2001; 79: 21421.

[2]. Resnikoff S, Pascolini D, Etya'ale D, Kocur I, Pararajasegaram R, Pokharel GP, Mariotti SP. Global data on visual impairment in the year 2002.Bull World Health Organ. 2004 Nov; 82(11):844-51.

[3]. Oliva MS, Schottman T, Gulati M. Turning the tide of corneal blindness. Indian J Ophthalmol. 2012; 60(5)423-427

[4]. Abdull MM, Sivasubramaniam S, Murthy GV, Gilbert C, Abubakar T, Ezelum C, Rabiu MM; Nigeria National Blindness and Visual Impairment Study Group. Causes of blindness and visual impairment in Nigeria: the Nigeria national blindness and visual impairment survey. Invest Ophthalmol Vis Sci. 2009 Sep; 50(9):4114-20.

[5]. Yew Y-W, Saw S-M, Pan J C-H, Shen H-M, Lwin M, Yew M-S, Heng W-J. Knowledge and beliefs on corneal donation in Singapore adults. Br J Ophthalmol 2005; 89:835-840.

[6]. Yorston D, Wood M, Foster A. Penetrating keratoplasty in Africa: graft survival and visual outcome. Br J Ophthalmol 1996; 80:890-894

[7]. Okoye OI, Maduka-Okafor FC, Eze BI. What does the medical student know about eye donation/corneal transplant? The University of Nigeria scenario. West Indian Med J. 2010 Jan; 59(1):41-4. 
[8]. Waziri-Erameh JM, Ernest AO, Edema OT. Knowledge and Attitude of Nigerian Ophthalmologists towards Cornea Donation and Corneal Graft. Journal of Medicine and Biomedical Research 2007; 5 (1\&2): 26-34

[9]. Sign MM, Rahi M, Pagare D, Ingle G.K. Medical Students' perception on eye donation in Delhi. India J Ophthalmol 2007; 55:4952.

[10]. Dhaliwal U. Enhancing eye donation rates. Training students to be motivators. Indian J Ophthalmol 2002; 50:209-12.

[11]. Gupta A, Jain S, Jain T, Gupta K. Awareness and perception regarding eye donation in students of a nursing college in Bangalore. Indian J Community Med 2009; 34:122-5.

[12]. Singh P, Kumar A, Pandey CM, Chandra H. Level of awareness about transplantation, brain death and cadaveric organ donation in hospital staff in India. Prog Transplant. 2002;12:289-92.

[13]. Rodríguez-Villar C, Paredes D, Ruiz A, Alberola M, Montilla C, Vilardell J, Manyalich M, Miranda B. Attitude of health professionals toward cadaveric tissue donation. Transplant Proc. 2009 Jul-Aug; 41(6):2064-6.

[14]. Dandona R, Dandona L, Naduvilath TJ, McCarty CA, Rao GN. Awareness of eye donation in the urban population In India. Aust N Z J Ophthalmol. 1999; 27:166-9.

[15]. Bharti MK, Reddy SC, Tajunisah I, Ali NAM. Awareness and Knowledge on Eye Donation among University Students. Med J Malaysia. 2009; 64 (1): 41-45.

[16]. Bhandary S, Khanna R, Rao AK, Rao LG, Lingam KD, Binu V. Eye donation -Awareness and willingness amongst attendants of patients at various clinics in Melaka, Malaysia. Indian J Ophthalmol. 2011;59:41-5.

[17]. Basu PK, Hazariwala KM, Chipman ML. Public attitudes towards donation of body parts, particularly the eye. Canadian Ophthalmol 1989;24:216-20

[18]. Gaum L, Reynolds I, Jones MNA, Clarkson AJ, Gillan HL, Kaye SB. Tissue and corneal donation and transplantation in the UK. Br. J. Anaesth. (2012) 108 (suppl 1): 143-147.

[19]. Kent B, Owens RG. Conflicting attitudes to corneal and organ donation: A study of nurses' attitudes to organ donation. Int J Nurs Stud 1995; 32: 484-492

[20]. Verble M, Worth J. Biases among hospital personnel concerning donation of specific organs and tissues: Implications for the donation discussion and education. J Transpl Coord 1997; 7: 72-77.

[21]. Verble M, Worth J. Reservations and preferences among procurement professionals concerning the donation of specific organs and tissues. J Transpl Coord 1997; 7: 111-115.

[22]. Lawlor, M., Kerridge, I., Ankeny, R., Dobbins, T. A. and Billson, F. (2010), Specific Unwillingness to Donate Eyes: The Impact of Disfigurement, Knowledge and Procurement on Corneal Donation. American Journal of Transplantation, 10: 657-663

[23]. Tandon R, Verma K, Vanathi M, Pandey RM, Vajpayee RB. Factors affecting eye donation from postmortem cases in tertiary care hospital. Cornea. 2004;23:597-601.

[24]. Gogate B, Gogate P. Eye donation: Mere awareness and willingness not enough. Only a catalyst can improve corneal harvesting rates. Indian J Ophthalmol. 2011 Jul-Aug; 59(4): 332-333.

[25]. Gogate B, Gogate P, Deshpande M. Eye donation program through faith leaders. Br J Ophthalmol. 2008; 92:867-8

[26]. Lwin MO, Williams JD, Lan LL. Social marketing initiatives: National Kidney Foundation's organ donation programs in Singapore. J Public Policy Marketing 2002; 21:66-77.

[27]. Golchet G, Carr J, Harris MG. Why don't we have enough cornea donors? A literature review and survey. Optometry. 2000; 71(5):318-328

[28]. Rocheleau CA. Increasing family consent for organ donation: findings and challenges. Prog Transplant. 2001; 11(3):194-200

[29]. Krieglstein TR, Neubauer AS, Welge-Lüssen U, Priglinger S, Kampik A, Priemer F. Cornea donation. Factors influencing consent [in German]. Ophthalmologe. 2001; 98(6):545-549.

[30]. Eniola MS, Ajobiewe AI. Attitude change and legislation as tools for enhancing eye donation rate for corneal transplantation. Nigerian Journal of Guidance and Counselling2010;15(1): 